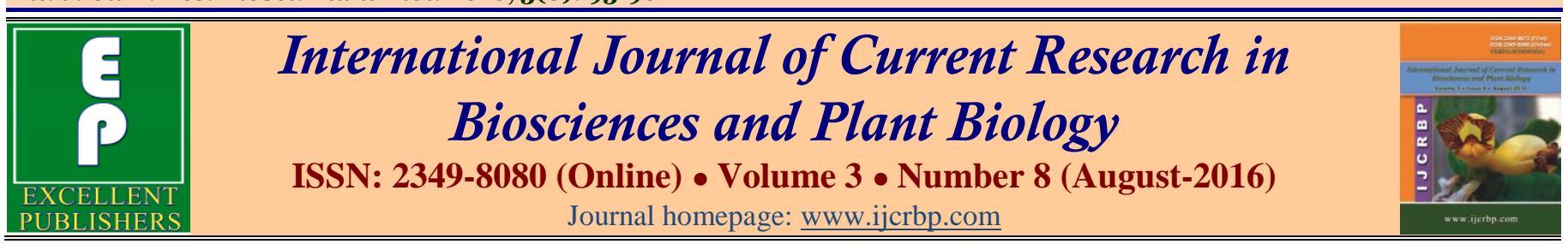

Review Article

doi: http://dx.doi.org/10.20546/ijcrbp.2016.308.015

\title{
Sodium Taurocholate as Novel Additive: A Right Choice for Ornamental Fish Feed
}

\author{
N. Daniel* \\ PhD Scholar, Fish Genetics and Biotechnology Division, ICAR-CIFE, Mumbai, India
}

*Corresponding author.

\begin{abstract}
The rearing of ornamental fishes is a common custom among the many people due to their coloration. Though many ornamental fishes are colorful in nature, when it comes to artificial tanks, they lose their bright coloration than that of wild. Despite many pigments are being a part of the ornamental feed for many years, the capacity of animals to acquire coloration depends on the increase in the digestion, absorption and metabolism of them. Supplementing pigments in the diet doesn't mean fish can be attained coloration and it depends on the presence of some dietary factors. The addition of such factors in the diet would influence the utilization of pigments in the animals. Sodium taurocholate is a novel additive which promotes the utilization of dietary carotenoids to the fish discussed in this article.
\end{abstract}

\section{Introduction}

Aquaculture is a swiftly growing worldwide industry, involving cultivation of varied fish for edible and decorative purposes. In recent years, the maximum amount of world fish production is supported by culture fisheries as trends in the capture fisheries got declined (FAO, 2016). Feed accounts for 50-60\% of the total expenditure in aquaculture and no doubt that success of fish cultivation will greatly depend on the development of proper feeds. Feed is basically prepared with composition of many ingredients contains varied nutrients and bioactive compounds that positively affect the biological status of the animals. Besides, supplementations of specific additives are added in the animal diet to alter the lifestyle of some species. For instance, carotenoids are used in feed of many ornamental fishes as well as salmon, rainbow trout, gold fish, red and gilthead sea bream for pigmentation.

\section{Article Info}

Accepted: 22 July 2016

Available Online: 06 August 2016

Ke y w o r d s

Additive

Ornamental fish feed

Sodium taurocholate 


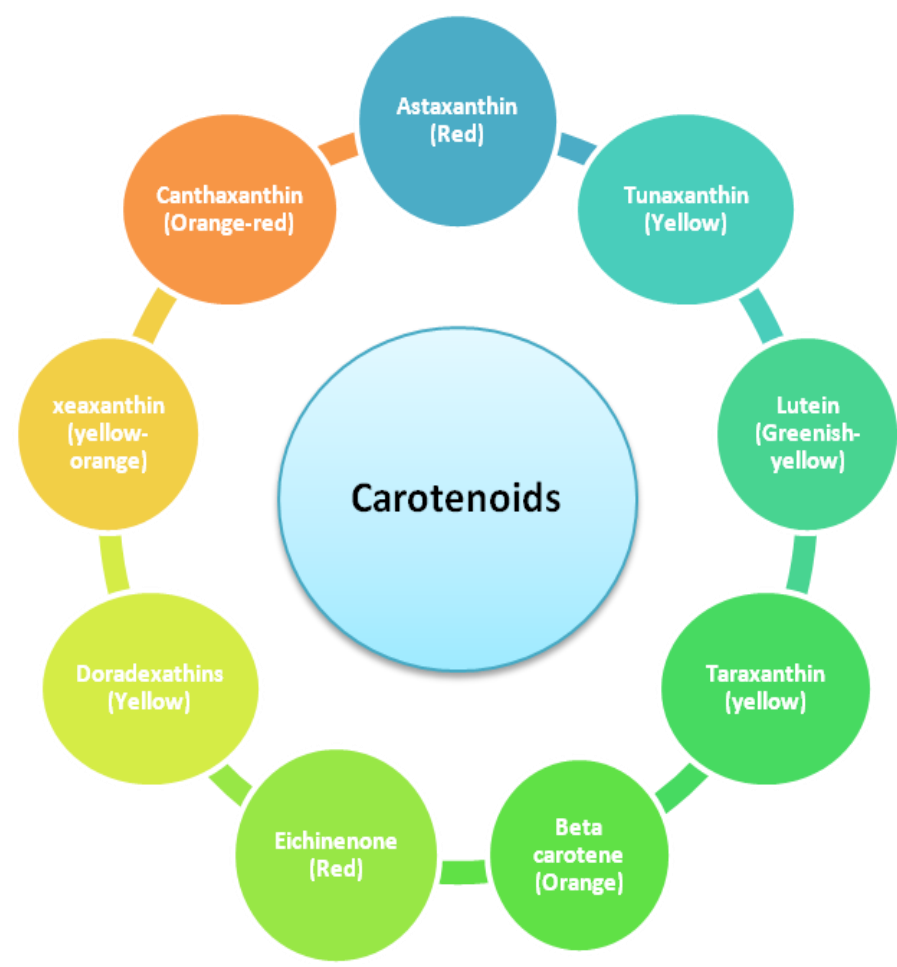

Fig. 1: Various types of carotenoids along with their colour properties (Source: García-Chavarría and Lara-Flores, 2013).

\section{Factors affecting the utilization of carotenoids}

It is unfortunate that the fish doesn't have the capacity to synthesize pigments de novo and therefore dietary sources are essential (Goodwin, 1986). Besides, the digestibility of pigments is less in fish. Digestion of carotenoids is very low (i.e. only 39 to $49.5 \%$ ) in salmon when fed (Torrissen et al., 1990). There are several factors that affect the utilization of carotenoids in fish (Leng and $\mathrm{Li}, 2006$ ). Therefore, the fish coloring is affected by the presence of certain compounds present in the feed, including fat content, vitamin E, vitamin A and some drugs. Through the addition of such substances in the diet, it is possible to promote the pigmentation in animals (Castenmiller and West, 1998). As suggested by Torrissen et al. (1990) adding higher lipid content of $4.1-23.0 \%$ in the feed along with carotenoids improve the digestibility of carotenoids. It established that astaxanthin was promoted the pigmentation in Xiphophorus helleri by the addition of lipids; but when exceeds $20 \%$ have no impact (Han, 2001).

\section{Why to add Na taurocholate in the diet?}

According to different author's pigmentation in the animals are not only directly related to the dietary intake of pigments in the diet (Parker, 1996). It depends on the external or other internal factors (Leng and $\mathrm{Li}, 2006$; Torrissen et al., 1990; Han, 2001).

It has been discovered recently that $\mathrm{Na}$ taurocholate in the diet promotes the absorption of astaxanthin. A recent study made in the blood parrot shows improved retention of carotenoids in the skins, tails, fins and muscles when $\mathrm{Na}$ taurocholate fed along with astaxanthin (Yang et al., 2012).

\section{Exactly how Na taurocholate can improve the pigment retention in fish?}

Carotenoids are hydrophobic in nature and have less solubility in the gastrointestinal tract of fish (Van den Berg, 1999). The absorption rate of carotenoids in the animals varies because it is subjective to the environmental and dietary factors. The capacity of carotenoid absorption in the intestine of fish is slow (Erdman, 1988). Carotenoids are derivatives of lipids and therefore, the absorption relies on micelle formation and micellar solubilisation (Choubert et al., 1994). The formation of micelles occurs by the bile salts and free fatty acids derived from the fatty acid during the fatty acid breakdown, so that solubilisation will take place and absorption is possible (Lakshman et al., 1996).

$\mathrm{Na}$ taurocholate is a conjugated product of taurocholate with sodium. Taurocholate may not be stable while feed processing and therefore it is conjugated with the stable form of sodium. Taurocholate is a category under bile salt family. Bile salt is an important component required for fat and fat-soluble nutrients as they decrease the surface tension of the liquids present in the gastro-intestinal tract by acting as a detergent between liquids and solid substances, so that absorption can take place (Zhou et al., 2001).

In the absence of bile salts, many fat soluble substances would be undigested and excreted. Bile salts are secreted by the liver, stored in the gallbladder and goes to the small intestine when requires. Fatty materials, including carotenoid pigments cannot be digested in the normal way, just like other water-soluble nutrients (Barbosa et al., 1999). So they need some helpers who can help in the digestion. Some studies evidenced that the addition of $\mathrm{Na}$ taurocholate in the diet promotes the absorption of carotenoids; in turn they improve the coloration of ornamental fishes (Lakshman et al., 1996; Chen et al., 2001; Yang et al., 2012). 


\section{Studies evidenced that $\mathrm{Na}$ taurocholate improves the absorption of carotenoids}

The study was conducted to identify the effect of $\mathrm{Na}$ taurocholate and free fatty acids on the absorption of $\beta$ carotene and lutein. The isolated small intestinal mucous cells were successfully cultured with these two carotenoid sources and witnessed that the addition of $\mathrm{Na}$ taurocholate and free fatty acids improves the absorption rate. It optimized from the study that $\mathrm{Na}$ taurocholate at the rate of $3 \mathrm{mM}$ and $10 \mathrm{mM}$ improves the $\beta$-carotene and lutein respectively. Similarly, oleic/stearic fatty acids at the rate of 100:0 and 3:1 improve the $\beta$-carotene and lutein respectively. More than these amounts tend to decrease the rate of absorption (Chen et al., 2001). The study conducted in the basal diet with $4 \%$ astaxanthin plus $>400 \mathrm{mg} / \mathrm{kg} \mathrm{Na}$ taurocholate enhances the degree of astaxanthin absorption and pigmentation in blood parrot than that of astaxanthin or $\mathrm{Na}$ taurocholate alone (Yang et al., 2012). It was also observed in ferrets that the addition of 0.5 to $1 \%$ of $\mathrm{Na}$ taurocholate in the diet promoted the carotenoid absorption threefold higher (Lakshman et al., 1996).

\section{Is Na taurocholate important only to ornamental fish feed?}

No doubt that pigments have an equal role in the farming aquatic animals. It was reported by several authors that incorporating the carotenoids in the feed promote the muscle or fillet quality of fishes (García-Romero et al., 2014; Spinelli et al., 1974; Coral et al., 1997). By considering the faded fillet color, the export values of some farming fishes are discouraged. Due to the potential role of the pigments in the flesh coloration, different places work has been established in this area. Recently attempts have been made at ICAR-CIFE, Mumbai, India wet laboratory in the Pangasius catfish with different carotenoid sources for improving the fillet coloration. Despite the positive results obtained in these studies, the requirement of carotenoids must be further optimized by studying with $\mathrm{Na}$ taurocholate as a novel source of the additive. This would be the new area, need special research interest.

\section{Advantages of using $\mathrm{Na}$ taurocholate as fish feed additive}

$>$ It has very good stability.

$>$ It can be stored for a long time (Yang et al., 2012).

$>$ The degree of water absorption and oxidation rate is less as compared to vitamin $\mathrm{E}$ and fat.

$>$ It also has antibacterial and immunostimulatory action (Xue et al., 2004).

$>$ The role of $\mathrm{Na}$ taurocholate is very specific and therefore may have high sensitivity will act on the promotion of carotenoid utilization.

\section{Recommendations and concluding remarks}

Recent research in feed nutrition is more focus on finding out the potential additives that improve the quality of feed. Though their applications claimed to have the beneficial impact in aquaculture, the addition of each additive also raises the costs of feed. To be economically sustainable, the feed has to be prepared with the optimum ingredients and additives without affecting both nutrition and quality. Till now research conducted in response to the pigmentation used higher levels of pigments in the diet. The application of pigments in the fish feeds is costly. Besides, fish have very limited capacity to digest carotenoids. Therefore, carotenoids in the diet need not be wasted. It is a great advantage that the addition of $\mathrm{Na}$ taurocholate along with carotenoids in the diet minimizes the wastage of supplemented carotenoids and promotes greater pigmentation to the fish.

Apart from the role in carotenoid utilization and fat digestion, $\mathrm{Na}$ taurocholate also has a role in the antibacterial and immunostimulatory action. The supplementation of immunostimulants to the feed got momentum in the recent years. In this connection, it would be feasible if supplementing this additive may replace some expanses of currently used immunostimulants in the fish feed. In this fashion, it has a great potential to reduce the feed costs as well; but require research studies.

The previous studies confirmed the dietary carotenoids increase the absorption and retention of pigments when fed with Na taurocholate. Therefore, it is concluded that considerable studies must be focused on these aspects and optimum inclusion level of $\mathrm{Na}$ taurocholate required for the carotenoid based supplemented diet should be carefully studied and recommended to the feed formulators to place $\mathrm{Na}$ taurocholate as an important additive in the fish feeds to promote the coloration of aquatic animals.

\section{Conflict of interest statement}

Author declares that he has no conflict of interest. 


\section{References}

Barbosa, M.J., Morais, R., Choubert, G., 1999. Effect of carotenoid source and dietary lipid content on blood astaxanthin concentration in rainbow trout (Oncorhynchus mykiss). Aquacult. 176(3), 331-341.

Castenmiller, J.J., West, C.E., 1998. Bioavailability and bioconversion of carotenoids. Annu. Rev. Nutr. 18(1), 19-38.

Chen, B., Zhou, G.H., Liu, Q., 2001. Study on the effect of carotenoid, sodium taurocholate and free fatty acids on carotenoids uptake by intestinal cells in vitro. Acta Zoonutr. Sinica. 2, 013.

Choubert, G., Milicua, J.C., Gomez, R., 1994. The transport of astaxanthin in immature rainbow trout Oncorhynchus mykiss serum. Comp. Biochem. Physiol. 108A, 245-248.

Clydesdale, F.M., 1993. Color as a factor in food choice. Crit. Rev. Food Sci. Nutr. 33, 83-101.

Coral, H.G., Hubermann, A., De la Lanza, G., Monroy-Ruiz, J., 1997. Pigmentation of the rainbow trout (Onorhynchus mykiss) with oil extracted astaxanthin from the langostilla (Pleurocondes planipes). Arch. Latinoamericanos Nutr. 47, 237-241.

Erdman, Jr., J.W., 1988. The physiologic chemistry of carotenes in man. Clin. Nutr. 7, 101-106.

FAO, 2016. The State of World Fisheries and AquacultureContributing to Food Security and Nutrition for All, FAO. pp.1-24.

García-Chavarría, M., Lara-Flores, M., 2013. The use of carotenoid in aquaculture. Res. J. Fisheries Hydrobiol. 8, 38-49.

García-Romero, J., Ginés, R., Izquierdo, M., Robaina, L., 2014. Marine and freshwater crab meals in diets for red porgy (Pagrus pagrus): Effect on fillet fatty acid profile and flesh quality parameters. Aquacult. 420, 231-239.

Goodwin, T.W., 1986. Metabolism, nutrition, and function of carotenoids. Annu. Rev. Nutr. 6(1), 273-297.

Han, L., Yang, C., Ou, Z., 2001. Progress in biosynthetic pathway and its biological functions of plant carotenoid. J. Biol. 19(6), 1-3.
Lakshman, M.R., Liu, Q.H., Sapp, R., Somanchi, M., Sundaresan, P.R., 1996. The effects of dietary taurocholate, fat, protein, and carbohydrate on the distribution and fate of dietary $\beta$-carotene in ferrets. Nutr. Cancer. 26, 49-61.

Leng, X.J., Li, X.Q., 2006. The recent advance of aquatic animal pigmentation. J. Fisheries China. 1, 021.

Parker, R.S., 1996. Absorption, metabolism, and transport of carotenoids. FASEB J. 10(5), 542-551.

Saito, A., Regier, L.W., 1971. Pigmentation of brook trout (Salvelinus fontinalis) by feeding dried crustacean waste. J. Fisheries Board Canada. 28(4), 509-512.

Schiedt, K., 1998. Absorption and metabolism of carotenoids in birds, fish and crustaceans. Carotenoids. 3, 285-358.

Spinelli, J., Lehman, L., Wieg, D., 1974. Composition, processing, and utilization of red crab (Pleuroncodes planipes) as an aquacultural feed ingredient. J. Fisheries Board Canada. 31(6), 1025-1029.

Sylvia, G., Morrisey, M.T., Graham, T., Garcia, S., 1996. Changing trends in seafood markets: the case of farmed and wild salmon. J. Aquatic Food Prod. Technol. 5, 49-63.

Torrissen, O.J., Hardy, R.W., Shearer, K.D., Scott, T.M., Stone, F.E., 1990. Effects of dietary canthaxanthin level and lipid level on apparent digestibility coefficients for canthaxanthin in rainbow trout (Oncorhynchus mykiss). Aquacul. 88(3), 351-362.

Van den Berg, H., 1999. Carotenoid interactions. Nutr. Rev. 57(1), 1-10.

Xue, Y., Li, P.F., Guan, H., 2004. Anti-inflammatory action mechanism of taurocholic acid. J. Inner Mongolia Agric. Univ. 26, 13-16.

Yang, H., Mu, X., Luo, D., Hu, Y., Song, H., Liu, C., Luo, J., 2012. Sodium taurocholate, a novel effective feed-additive for promoting absorption and pigmentation of astaxanthin in blood parrot (Cichlasoma synspilum $q \times$ Cichlasoma citrinellum $\precsim$ ). Aquacult. 350, 42-45.

Zhou, L., Zhou, G., Chen, B., 2001. Effects of bile salt on intestinal absorption of carotenoids in goats. J. Nanjing Agric. Univ. 25(3), 61-64.

\section{How to cite this article:}

Daniel, N., 2016. Sodium taurocholate as novel additive: A right choice for ornamental fish feed. Int. J. Curr. Res. Biosci. Plant Biol. 3(8), 93-96. doi: http://dx.doi.org/10.20546/ijcrbp.2016.308.015 